\title{
Review
}

Stereotactic

and Functional

Neurosurgery
Stereotact Funct Neurosurg 2019;97:49-54

DOI: 10.1159/000496157
Received: August 29, 2018

Accepted after revision: December 9, 2018

Published online: February 13, 2019

\section{The Origins of Human Functional Stereotaxis: A Reappraisal}

\author{
Lara Rzesnitzek $^{a} \quad$ Marwan Hariz $^{b, c} \quad$ Joachim K. Krauss ${ }^{d}$ \\ ${ }^{a}$ Charité Psychiatric University Hospital at St. Hedwigs Hospital, University Medicine Charité, Berlin, Germany; \\ bUCL Institute of Neurology, London, UK; ' Department of Clinical Neuroscience, Umeå University, Umeå, Sweden; \\ ${ }^{\mathrm{d}}$ Department of Neurosurgery, Medical School Hannover, Hannover, Germany
}

\section{Keywords}

Psychosurgery · Functional neurosurgery - Leucotomy · Thalamotomy $\cdot$ Stereotaxy $\cdot$ History $\cdot$ Stereotactic surgery

\begin{abstract}
In order to shed light on the first application of human functional stereotactic neurosurgery, whether it was in the realm of movement disorders, as has been claimed repeatedly, or in the realm of psychiatry, a review of the original scholarly literature was conducted. Tracking and scrutinising original publications by Spiegel and Wycis, the pioneers of human stereotactic neurosurgery, it was found that its origin and the very incentive for its development and first clinical use were to avoid the side effects of frontal leucotomy. The first applications of functional stereotactic neurosurgery were in performing dorsomedial thalamotomies in psychiatric patients; it was only later that the stereotactic technique was applied in patients with chronic pain, movement disorders and epilepsy. Spiegel and Wycis' first functional stereotactic operations were for obsessive-compulsive disorder, schizophrenia, and other psychiatric conditions.
\end{abstract}

(c) 2019 S. Karger AG, Basel

\section{Introduction}

Several authors, including two of the present authors (M.H. and J.K.K.) have previously published about the history of human functional stereotactic neurosurgery and stated that the original use of this technique was in the treatment of patients with movement disorders: it was stated that Spiegel and Wycis, who pioneered human functional stereotactic neurosurgery, used their newly devised stereotactic technique first for the treatment of Huntington's chorea [1-8]. Hence, one of the previously published statements read: "Although 'stereotaxic' surgery (as it was then spelled) was conceived for psychosurgery, the first patient had Huntington's chorea" [3].

Given that the incentive of Spiegel and Wycis in 1947 was to design a human stereotactic apparatus for psychosurgical use, and considering that subsequent historical reviews asserted that the first implementation of human functional stereotaxy was in patients with movement disorders, we set to perform an in-depth survey of the original scientific literature to find out what were really the first human applications of the newly devised stereotactic technique.

\section{KARGER}

(c) 2019 S. Karger AG, Basel

E-Mail karger@karger.com

www.karger.com/sfn
Lara Rzesnitzek, MD

Charité Psychiatric University Hospital at St. Hedwigs Hospital

University Medicine Charité, Grosse Hamburger Strasse 5-11

DE-10115 Berlin (Germany)

E-Mail lara.rzesnitzek@ charite.de 


\section{Stereotaxic Apparatus for Operations on the Human Brain ${ }^{1}$}

\section{E. A. Spieger, H. T. Wycts, M. Marks, and A. J. Lee \\ Department of Experimental Neurology, Temple University School of Medicine, Philadelphia}

Exposure of subcortical areas usually necessitates rather extensive operations. It seemed desirable, therefore, to adapt the stereotaxic technic for use on the human brain. This technic, employed thus far for animal experimentation only (I), permits one to insert a wire or a cannula accurately into a desired subcortical area with minimal injury to the cerebral a cortex or the white matter.

This apparatus is being used for psychosurgery. In a series of patients studied in collaboration with $\mathrm{H}$. Freed, lesions have been placed in the region of the medial nucleus of the thalamus (medial thalamotomy) in order to reduce the emotional reactivity by a procedure much less drastic than frontal lobotomy (2). The results so far obtained are promising. Further applications of the stereotaxic technic are under study, e.g. interruption of the spinothalamic tract in certain types of pain or phantom limb; production of pallidal lesions in involuntary movements; electrocoagulation of the Gasserian ganglion in trigeminal neuralgia; and withdrawal of fluid from pathological cavities, cystic tumors.

\section{References}

1. Hovstex, V., and Clnexz, R. H. Brain ,1908, 31, 45; Runson, S. W. Psychiat. nowrol. Bl., Amst., 1934, 38, 534.

2. Sprzorx, E. Preliminary report, American Neurological Association, b

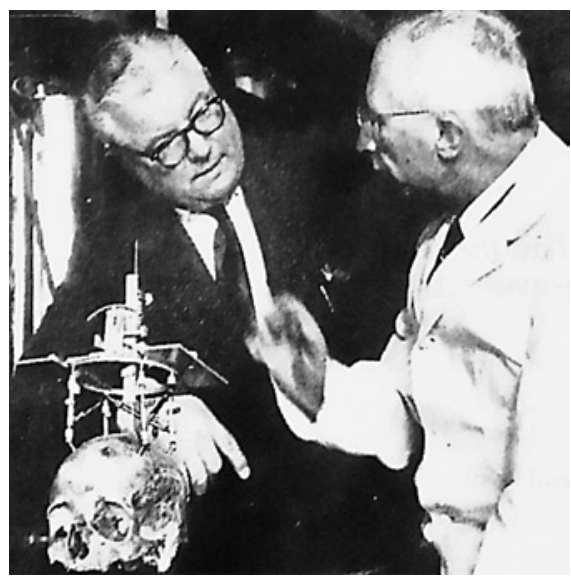

Fig. 2. Spiegel and Wycis discussing their stereotactic apparatus. Reprinted courtesy of the World Society for Stereotactic and Functional Neurosurgery, Photo Archive.

perform psychosurgery; they wrote: "This apparatus is being used for psychosurgery. In a series of patients studied in collaboration with $\mathrm{H}$. Freed, lesions have been placed in the region of the medial nucleus of the thalamus (medial thalamotomy) in order to reduce the emotional reactivity by a procedure much less drastic than frontal lobotomy" (Fig. 1a, b, 2) [9].

"Lobotomy" was the term for leucotomy used in North America. It had been coined by the neurologist and psychiatrist Walter Freeman (1895-1972) who had introduced the method in the USA in cooperation with neurosurgeon James Watts (1904-1994) in 1936. By the end of the 1940s, lobotomy as a treatment for schizophrenia, depression, "obsessions and compulsions and other neuroses" was widely used and performed in more than half of all American psychiatric hospitals or institutions $[10,11]$. The rationale for frontal lobotomy was to try to improve psychiatric symptoms by reducing "emotional reactivity" [12]. However, severe side effects, such as apathy, psychomotor slowing, amnestic disorders, and faecal and urinary incontinence, were not uncommon following lobotomy [10, 11].

It was explicitly to avoid these severe side effects of frontal leucotomy, that Spiegel and Wycis introduced the stereotactic method. In his reminiscences in 1983, Spiegel wrote:

"In the winter of 1947, I watched a prefrontal lobotomy performed and I was appalled by the resulting extensive brain damage and by the severe personality changes. It occurred to me that a reduction of the emotional and behavioural disturbances attempted by lobotomy could be obtained also by small lesions of the thalamic dorsomedial nucleus that forms a circuit with the frontal lobe. Such a lesion would avoid severance of the association fibers caused by lobotomy" [13].
In their article in Science in 1947, neurologist Ernst A. Spiegel (1895-1985) and neurosurgeon Henry T. Wycis (1911-1971) described their stereotactic apparatus for the first time. It was explicitly introduced as a device to
Rzesnitzek/Hariz/Krauss 
Spiegel and Wycis' Science article from 1947 already cited a "preliminary report," given upon the occasion of a discussion at a meeting of the American Neurological Association in 1947 (cf. Fig. 1a, b). Here, Spiegel mentions the results after using an adaption of the stereotactic method to the human brain in "five patients that Dr. $\mathrm{H}$. Freed has sent to us, one catatonic, two cases of obsessive compulsive neurosis, a child with mental deficiency and severe agitation, and a schizophrenic with paranoid and catatonic traits" [14].

In the introduction to his book Guided Brain Operations [15], published in 1982, Spiegel writes that the first human stereotactic operation was performed by Spiegel and Wycis in the spring of 1947. In line with this source, Spiegel and Wycis presented their results also entitled as "Thalamotomy for Mental Disorders" at the 1st International Conference for Psychosurgery in Lisbon in the summer of 1948 [16]. Delineating their procedure, Spiegel and Wycis argued that even if animal experiments on cats and monkeys with lesions placed in the dorsomedial nucleus had shown no harmful effect, they had decided to go "only step by step, producing in the first case (compulsive obsessive state and depression) only one coagulation on each side, in the second patient (catatonic schizophrenia) four lesions on the left and one on the right, in the third (mental deficiency with agitation) two lesions in each dorsomedial nucleus" [16].

Also, at a further meeting of the American Neurological Association, published in the Transactions in 1948, where Spiegel and Wycis labelled the new method as "stereoencephalotomy," all cases of the first section were psychiatric ones; remarkably, these cases were exactly the same cases as reported in the earlier lectures of Spiegel and Wycis: "the first case (compulsive obsessive state and depression) [...] the second (catatonic schizophrenia)" [17]. The second section presented 2 cases of thalamotomy in refractory pain and the third section 2 cases in convulsive disorders of subcortical origin [17].

During the following discussion, neurologist Walter Freeman congratulated Spiegel and Wycis on having "gone a long distance towards making understandable the relationship between the thalamus and the disorders of the psyche in the psychoses" [17]. Freeman even stressed that after an autopsy study of a series of leucotomy cases, which showed significant retrograde degeneration in the thalamus, he himself had "the idea that the effect of lobotomy upon the patient was due to the effect upon the thalamus," an idea which was cited later by Freeman as the theory of lobotomy in the second edition of Psychosurgery in 1950 [12].

Origins of Human Stereotaxis
Departments of Experimental Neurology and Neurosurgery Temple Vniversity Medical School and Hospital, Philadelphia.

Thalamotomy and Pallidotomy for Treatment of Choreic Movements.

\section{By}

B. A. Spiegel and H. T. Wycis.

Using our stereolaxic method adapted for humans ', we have devised new approaches for treatment of choreic and athetotic movements whereby electrolytic lesions were placed in the region of the dorsomedial nuclei (Thalamotomy), or in the region of the globus pallidus (Pallidotomy).

Fig. 3. Section of Spiegel and Wycis' 1952 article dating the first stereotactic intervention for Huntington's disease on December 9 , 1948 [19].

That "stereotaxy" for Huntington's chorea was performed only after the method had been used in psychiatric patients can also be concluded from a report at the Neurological Society meeting in Philadelphia in March 1949. Spiegel and Wycis mentioned that, in the Huntington patients, they had chosen to perform "a two stage operation" with pallidal and thalamic lesions because they "had previously observed that lesions of the dorsomedial nuclei of the thalamus are able to diminish the emotional reactivity" [18].

Tracing the sources of Spiegel and Wycis further, it appeared that the first stereotactic surgery to treat Huntington's disease was performed on Thursday, December 9, 1948, and not in 1947 as claimed in 2 recent articles by one of the present authors (M.H., mea culpa) $[6,7]$. In their article "Thalamotomy and Pallidotomy for Treatment of Choreic Movements," published in 1952 (Fig. 3), Spiegel and Wycis clearly state that case 1, a "53-year-old white male" was operated on December 9, 1948, by the "stereotaxic method": "extensive electrolytic lesions were placed in the left dorsomedial nucleus of the thalamus and one droplet of $50 \%$ alcohol was injected in the region of right globus pallidus at the level of the anterior commissure" [19].

In conclusion, at least during the first 2 years since 1947, psychiatric indications and then severe pain, but not movement disorders, were the primary focus for stereotactic techniques. Subsequently, at the Anglo-American Symposium on Psychosurgery, Neurophysiology and Physical Treatments in Psychiatry of the Section of Psychiatry of the Royal Society of Medicine, in London in September 1949 (Fig. 4a, b), Spiegel and Wycis summarized about 60 stereotactic psychosurgery procedures in

Stereotact Funct Neurosurg 2019;97:49-54 DOI: $10.1159 / 000496157$ 

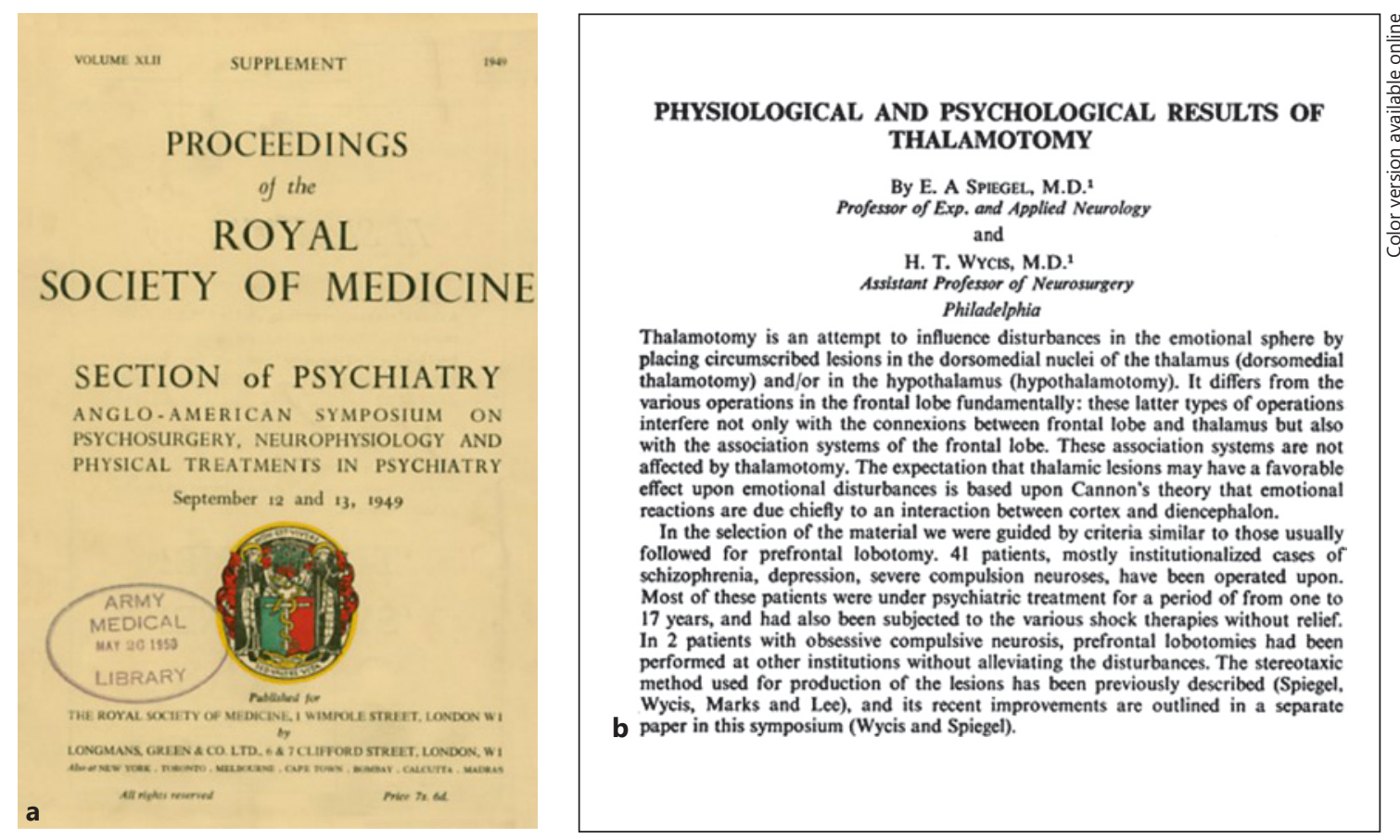

Fig. 4. a Cover page of the Anglo-American Symposium on Psychosurgery of the Royal Society of Medicine [20]. b Section of the first page of the reprint of Spiegel and Wycis' lecture at the Royal Society of Medicine [20].

"41 patients, mostly institutionalized cases of schizophrenia, depression, severe compulsion neuroses" [20]. Some of the patients with schizophrenia had relapsed after the initial surgery and had been re-operated, using also hypothalamic lesions.

At the 4th International Congress of Neurology in Paris in 1949, Spiegel and Wycis presented their results with a specific focus on chronic pain [21]. Here, the French psychiatrist turned neurosurgeon Jean Talairach (1911-2007) lectured about his own stereotactic system for the electrocoagulation of the posterior ventral thalamic region for the treatment of therapy-resistant pain [22]. At that Paris congress, the neurologist Alphonse Baudouin (1876-1956) and the neurosurgeon Pierre Puech (1897-1950) presented also cases of thalamotomy, both for pain and for schizophrenia [23]. It should be noted that by the end of the 1940s, two other types of stereotactic systems were developed: one designed by Lars Leksell (1907-1986) in Sweden and the other by Traugott Riechert (1905-1983) in Germany; in both cases, the primary applications of the stereotactic device were for psychiatric disorders, including schizophrenia, depression, "obsessions, compulsions and neurotic fear" [24-27].

\section{Discussion}

Our reappraisal of the early years of human stereotactic neurosurgery revealed that its first applications were in the domain of psychiatric illness, not movement disorders. In this respect, it is interesting to note that a famous illustration widely used in publications was a photograph initially published in The Times' LIFE Magazine in August 1948 showing Spiegel and Wycis performing a stereotactic procedure on a patient [28]. This photograph had the headline "New Brain Operation for Mental Illness" (Fig. 5). However, this picture that became commonly used for illustration in textbooks and reviews on the history of stereotactic neurosurgery is shown without its headline [5, 29]! Maybe the main reason for omitting the label of that famous illustration in subsequent reproductions was that any psychosurgery, ever since the era of leucotomy, had become taboo?

Be it as it may, the arguments presented by the pioneers in favour of the use of the stereotactic method to perform dorsomedial thalamotomy were that (a) leucotomy was therapeutically "effective" as it reduces emotional reactivity; (b) this effect was finally due to a retrograde degeneration of neurons in certain thalamic nuclei, such 


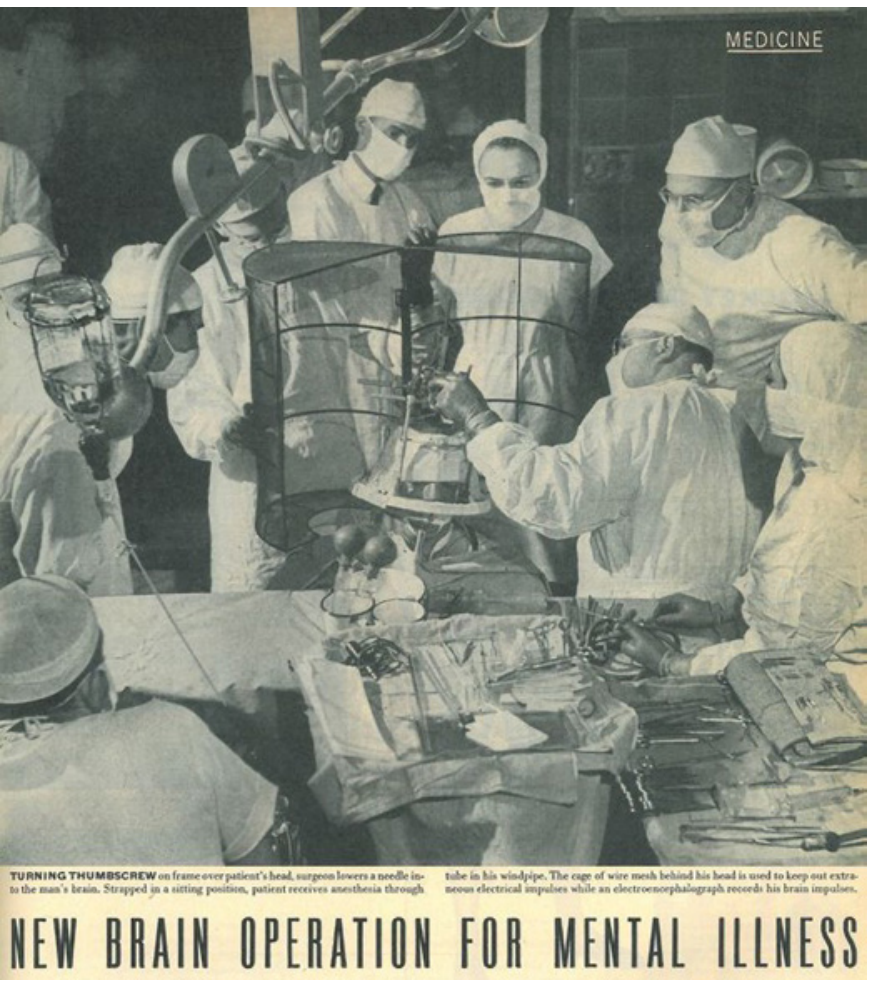

Fig. 5. Section of page 57 of the August 16th issue, 1948, of the LIFE Magazine [28].

as the dorsomedial nucleus of the thalamus; and (c) the side effects of leucotomy resulted from the vast and indiscriminate destruction of frontal cortical areas and their connections. Hence, targeted lesions directed at the subcortical thalamic nuclei promised similar effects with less side effects. Consequently, dorsomedial thalamotomy was applied and studied in schizophrenia, other psychiatric disorders and also severe pain. And indeed, only after it had been shown to be efficacious in psychosurgery was it used to treat symptoms in patients with Hunting- ton's chorea. With the neuroanatomical and neurophysiological knowledge available from the non-stereotactic basal ganglia surgeries for Parkinson's disease by Russel Meyers (1905-1999), the stereotactic technique then was quickly used to target other subcortical areas, including the pallidum, the ansa lenticularis, the motor thalamus and their interconnecting pathways [30, 31].

Remarkably, while "stereotaxy" at its inception promised a major impact in the field of psychiatry, the 1949 Nobel price was nevertheless awarded for the invention of standard prefrontal leucotomy. Stereotactic surgery, born as a limited focussed psychosurgical procedure, became dominant as a surgical procedure for Parkinson's disease and movement disorders. Despite its stated origins and goals and its declared aim to avoid the side effects of leucotomy, its applications in psychiatric surgery have always been, and still are, hampered by the stigma of leucotomy.

\section{Statement of Ethics}

The authors have no ethical conflict to disclose.

\section{Disclosure Statement}

L.R. has no conflict of interest to declare. J.K.K. is a consultant to Medtronic and Boston Scientific and received honoraria from St. Jude/Abbott. M.H. received honoraria and travel expenses from Medtronic, St. Jude, Boston Scientific and Elekta for speaking at meetings.

\section{Author Contributions}

L.R.: researching the historical details, drafting and revising the manuscript. J.K.K.: drafting and revising the manuscript. M.H.: drafting and revising the manuscript.

\section{References}

1 Gildenberg PL. The history of surgery for movement disorders. Neurosurg Clin N Am. 1998 Apr;9(2):283-94

2 Gildenberg PL. Spiegel and Wycis - the early years. Stereotact Funct Neurosurg. 2001; 77(1-4):11-6.

3 Gildenberg PL. The birth of stereotactic surgery: a personal retrospective. Neurosurgery. 2004 Jan;54(1):199-207.

4 Nashold BS. The history of stereotactic neurosurgery. Stereotact Funct Neurosurg. 1994; 62(1-4):29-40.
5 Gildenberg PL, Krauss JK. History of Stereotactic Surgery. In: Lozano AM, Gildenberg PL, Tasker RR, editors. Textbook of stereotactic and functional surgery. Berlin, Heidelberg: Springer; 2009. pp. 3-33.

6 Hariz M, Tabrizi S. Patients with Huntington's disease pioneered human stereotactic neurosurgery 70 years ago. Brain. 2017 Sep; 140(9):2516-9.

7 Cif L, Hariz M. Seventy years of pallidotomy for movement disorders. Mov Disord. 2017 Jul;32(7):972-82.
8 Krauss JK, Grossman RG. Surgery for Parkinson's disease and hyperkinetic movement disorders. In: Jankovic J, Tolosa E, editors. Parkinson's disease and movement disorders. Philadelphia: Lippincott, Williams and Wilkins; 2002. pp. 640-62.

9 Spiegel EA, Wycis HT, Marks M, Lee AJ. Stereotaxic Apparatus for Operations on the $\mathrm{Hu}$ man Brain. Science. 1947 Oct;106(2754):34950. 
10 Swayze VW 2nd. Frontal leukotomy and related psychosurgical procedures in the era before antipsychotics (1935-1954): a historical overview. Am J Psychiatry. 1995 Apr;152(4): 505-15.

11 Valenstein E. Great and desperate cures: the rise and decline of psychosurgery and other radical treatments for mental illness. New York: Basic Books; 1986.

12 Freeman W, Watts J. Psychosurgery. In the Treatment of mental disorders and intractable pain. 2nd ed. Springfield (IL): Charles C. Thomas; 1950.

13 Spiegel EA. This week's citation classic. 1983 Aug;33:325. Available from: http://garfield. library.upenn.edu/classics 1983 / A1983RB10700001.pdf

14 Spiegel EA. Preliminary report as discussion of: Karnosh LJ, Gardener WJ, Stowell A. The Effect of cerebral sympathectomy on organic brain diseases and psychoses. Trans Am Neurol Assoc. 1947;72:157-160, 159-160.

15 Spiegel EA. Guided brain operations. Philadelphia: Karger; 1982.

16 Spiegel EA, Wycis HT, Freed H. Thalamotomy for mental disorders. In: Psychosurgery 1st International Conference, August 4th-7th 1948 Lisbon. Lisbon: publisher unknown; 1949, p. 91-96.

17 Spiegel EA, Wycis HT, Freed H, Lee AJ. Stereoencephalotomy. Trans Am Neurol Assoc. 1948;73(73 Annual Meet.):160-3.
18 Spiegel EA, Wycis HT. Pallidothalamotomy in chorea. Arch Neurol Psychiatry. 1950 Aug; 64(2):295-6.

19 Spiegel EA, Wycis HT. Thalamotomy and pallidotomy for treatment of choreic movements. Acta Neurochir (Wien). 1952;2(3-4): 417-22.

20 Spiegel EA, Wycis HT. Physiological and psychological results of thalamotomy. In: The Royal Society of Medicine, editors. Proceedings of the Royal Society of Medicine, Supplement. Section of Psychiatry. Anglo-American symposium on psychosurgery, neurophysiology and physical treatments in psychiatry. London: Longmans, Green \& Co; 1949, p. 84 93.

21 Wycis HT, Spiegel EA. Mesencephalotomy and mesencephalothalamotomy for the treatment of unbearable pain. In: IVe Congrès Neurologique International, Paris, 5-10 Septembre 1949. Vol 3. Paris: Masson; 1949, p. 310-313.

22 Talairach J, Hecaen H, David M, Monnier M. Traitement de certaines algies rebelles par electrocoagulation de la region postéro-ventrale du thalamus [Treatment of some forms of chronic pain with electrocoagulation of the posterior-ventral thalamic region]. In: IVe Congrès Neurologique International, Paris, 5-10 Septembre 1949. Vol 2. Paris: Masson; 1949, p. 45-46.

23 Baudouin A, Puech P. Sur quelques essais de thalamotomie [Some trials of thalamotomy]. In: IVe Congrès Neurologique International, Paris, 5-10 Septembre 1949. Vol 2. Paris: Masson; 1949, p. 44-45.
24 Leksell L. A stereotactic apparatus for intracerebral surgery. Acta Chir Scand. 1949;99:22933.

25 Herner T. Treatment of mental disorders with frontal stereotaxic thermo-lesions - A follow up study of 116 cases. Copenhagen: Ejnar Munksgaard; 1961.

26 Riechert T, Wolff M. Über ein neues Zielgerät zur intrakraniellen elektrischen Ableitung und Ausschaltung [About a new device for guiding intracranial electrical mesurement and lesioning]. Eur Arch Psychiatry Clin Neurosci. 1951;186(2):225-30.

27 Riechert T. Die psychochirurgischen Eingriffe mit besonderer Berücksichtigung der gezielten Hirnoperationen [Psychosurgical interventions with special mention of guided brain operations]. Langenbecks Arch Surg. 1953;276(1):101-9.

28 Anonymous. New brain operation for mental illness. Times LIFE Magazine. 1948 Aug 16: 57-60.

29 Gildenberg PL. History repeats itself. Stereotact Funct Neurosurg. 2003;80(1-4):61-75.

30 Guridi J, Lozano AM. A brief history of pallidotomy. Neurosurgery. 1997 Nov; 41(5) 1169-80.

31 Redfern RM, Ruskin J. History of stereotactic surgery for Parkinson's disease. Br J Neurosurg. 1989;3(3):271-304 